\title{
Los procesos de regeneración urbana basados en la cultura en el centro de Monterrey [México]
}

DOI: $10.20396 /$ labore.v13i0.8654202

Submetido 12 ago. 2018.

Aceito 19 dez. 2018.

Publicado 03 jul. 2019.

\author{
Fabiola Rosamaría Garza-Rodríguez
$<$ https://orcid.org/0000-0001-5971-0478> \\ Universidad Politécnica de Cataluña / Barcelona [Cataluña] España
}

\section{RESUMEN}

En las últimas décadas, la cultura se ha utilizado como estrategia de regeneración urbana por ser un concepto permeable hacia otras áreas de desarrollo. Desde hace 30 años se manifiesta que el centro de Monterrey está en deterioro, por lo que el sector público ha realizado regeneraciones urbanas con fuerte implicación cultural. A pesar de la calidad y magnitud de los proyectos, estos no han logrado los objetivos esperados. En contraparte, surgen intervenciones urbanas por residentes locales que están logrando transformar la imagen urbana de manera positiva. Utilizando un método cualitativo se analizan y contrastan los proyectos de regeneración a partir de entrevistas a actores clave. Entre los principales resultados destaca que el centro cuenta con un alto potencial cultural que se ve disminuido por la falta de comunicación entre actores, los cuales, actuando en separado han contribuido a que la degradación en lugar de que cese, continúe.

PALABRAS CLAVE

Regeneración urbana. Cultura. Monterrey. Centro. desarrollo sostenible.

\section{Urban regeneration processes based in culture in Monterrey city center [México]}

\begin{abstract}
In recent decades, culture has been used as a strategy for urban regeneration because of its multidisciplinary approach. For 30 years it has been said that the center of Monterrey is deteriorated, so the public sector has carried out urban regeneration projects that we conclude, are part of cultural strategies. Despite the quality and magnitude of the projects, they have not achieved the expected objectives. In contrast, urban interventions that arise from local residents are transforming the urban fabric of some areas in the center in a positive way. Through a qualitative method, urban regeneration projects made in Monterrey city center are analyzed and contrasted with interviews made to key actors. Among the main results, highlight that the center has a high cultural potential that is diminished by the lack of communication between stakeholders, which by acting separately instead of reverse the urban degradation made it stronger.
\end{abstract}

\section{KEYWORDS}

Urban regeneration. Culture. Monterrey. Center. Sustainable development. 


\section{Introducción}

Las regeneraciones urbanas basadas en la cultura han sido ampliamente investigadas en contextos norteamericanos, europeos (García, 2004; Jones y Evans, 2008) y asiáticos (Kana, 2012; Jung et al., 2015). Aunque en el contexto latinoamericano existen investigaciones que estudian el fenómeno (Yúdice, 2008; Kanai y Ortega-Alcázar, 2009), hace falta generar más investigación, sobre todo, enfocada en los procesos en los que la cultura se manifiesta en la regeneración y en cómo son recibidas por residentes locales. Los mejores ejemplos de regeneraciones urbanas desde la cultura en Latinoamérica, son los casos de Medellín y Bogotá (Duque Franco, 2015), pero es necesario extrapolar la investigación hacia nuevos contextos, como el mexicano.

El área metropolitana de Monterrey (tercer área metropolitana más grande del país, ubicada al noreste de México) compuesta por doce municipios, concentra una población de casi cuatro millones y medio de habitantes. Su consolidación como enclave logístico, industrial y de negocios se favorece por su posición geográfica: está a menos de $200 \mathrm{~km}$ de la frontera con Estados Unidos. El sector público ha diversificado el desarrollo económico de la ciudad apostando a los sectores de servicios, conocimiento e innovación. Por otro lado, el centro de la ciudad sufre un fenómeno de despoblación junto con una precaria imagen urbana que lo expone como sitio en abandono y deterioro. Fenómeno que recuerda el concepto de 'ciudad dual' desarrollado por Castells (1991) y que visibiliza realidades alternas en una misma ciudad. Como respuesta a reducir lo más posible esa dualidad, desde la década de los 80 el sector público ha desarrollado proyectos de regeneración urbana en el centro para darle un giro orientado al sector residencial, de comercio y servicios con la finalidad de atraer inversión y así, detonar su vitalidad (Leal y Fitch Osuna, 2012).

Las problemáticas generalizadas en los centros de ciudades latinoamericanas como degradación, abandono y pérdida de población son áreas de oportunidad para fomentar su revitalización (García et al., 2016). La cultura se ha convertido en un área importante en la política urbana (Dinardi, 2012), porque permite generar estrategias que fomentan el potencial urbano, cultural e histórico del lugar. En ese sentido, este trabajo contribuye en comprender el papel de éstas regeneraciones y la forma en que se desarrollan en la ciudad latinoamericana específicamente en el caso del centro de Monterrey-. En relación a lo anterior, se proponen los siguientes objetivos:

- Analizar los procesos de regeneración urbana implementados en el centro de Monterrey en el periodo de 1980 a la fecha.

- Explorar discursos socio-urbanos desde la percepción de actores clave para construir una narrativa sobre los procesos de regeneración y las estrategias implementadas en donde la cultura se convierte en elemento clave de transformación urbana.

- Identificar la existencia de estrategias específicas que contribuyan en la sostenibilidad cultural del lugar.

La metodología parte de la revisión de trabajos académicos y documentos locales para construir los antecedentes y dibujar la situación actual del centro. Estas características se ven complementadas con entrevistas en profundidad realizadas a actores clave. Para el análisis de los procesos de regeneración se diferencian dos etapas: La primera, de 1980-2010, como la etapa donde inicia la apuesta por parte del sector público hacia la construcción de proyectos emblemáticos que impactan y promueven la imagen de la ciudad. La segunda, del 2013-actualidad, explora formas emergentes de regenerar el territorio, en donde se compara entre proyectos que ha realizado el sector público e intervenciones urbanas implementadas por residentes locales. El análisis es complementado con 10 entrevistas semi-estructuradas aplicadas a actores clave. Éstas recogen información sobre la percepción social del modelo urbano actual del centro de Monterrey, sobre las estrategias de regeneración urbana implementadas y sobre cómo la cultura se manifiesta como herramienta de regeneración urbana. La muestra se compone por académicos/investigadores en urbanismo (3), representantes de colectivos que defienden aspectos socio-urbanos del centro (3), arquitectos locales con rol activo en el desarrollo y construcción de proyectos en la zona (3) y un periodista dedicado a documentar temáticas relativas al desarrollo cultural del centro (1). Además del bagaje profesional de los actores, todos ellos son residentes del centro, lo cual aporta un valor agregado por ser usuarios permanentes del lugar. Las entrevistas se realizan de forma presencial y se llevan a cabo en diciembre de 2015 y enero de 2016 en Monterrey, México; la duración promedio es de entre 45 y 120 minutos, siendo audio grabadas para su posterior transcripción y análisis.

\section{El papel de la cultura en los procesos de regeneración urbana}

La regeneración urbana es un proceso sistémico y complejo cuyo objetivo es resolver problemáticas urbanas desde un enfoque integral mejorando las condiciones físicas, sociales, ambientales y económicas de la ciudad 
(Roberts, Sykes y Granger, 2016). Parte de una estrategia política que a modo de regulaciones y planeación promueve inversiones con la finalidad de transformar un lugar con deterioro físico, social o económico (Evans, 2005). Si bien, en un inicio buscan generar inversiones para mejorar y afianzar el crecimiento económico del área a regenerar (Jones y Evans, 2008; Pastak y Kährik, 2016), hoy en día sus objetivos van más allá de este aspecto, promoviendo a través de nuevas estrategias y enfoques — como la cultura (Blessi et al., 2012) — ciudades inclusivas y sostenibles. El reto urbano actual es crear ciudades compactas, saludables, equitativas, eficientes, creativas y cohesionadas (Evans, 2005; Florida, 2005); factores cualitativos y de bienestar que se ha demostrado, influyen de manera directa en la calidad de vida y resiliencia urbana (Heath et al., 2017). En las últimas décadas, la cultura se ha utilizado como instrumento, herramienta y proceso de regeneración urbana (Zukin, 1995; Bayliss, 2004; UN-Habitat, 2004; Miles, 2005: Pratt, 2009), aplicando estrategias ligadas a la creatividad, a medios de expresión artística, al desarrollo de identidad colectiva (Landry, 2003), a la implementación de políticas públicas culturales (Bianchini y Parkinson, 1993; Landry y Bianchini, 1995) y de gobernanza urbana (Degen y García, 2012). A partir de estrategias culturales se han generado métodos alternativos de desarrollo urbano y social, lo que ha devenido en una contribución hacia la sostenibilidad de la ciudad no solo por mejorar su forma y funcionamiento, sino también por mejorar la experiencia de vivir en ellas (Landry y Bianchini, 1995; Pethia, 2011).

Por una parte están las estrategias orientadas a planes de renovación urbana mediante la creación de proyectos emblemáticos o equipamientos culturales (Bianchini y Parkinson, 1993; Evans y Shaw, 2004; Duque Franco, 2015) para revitalizar un área urbana con la presencia de un ejemplar arquitectónico de marca, como por ejemplo, el caso del Guggenheim de Bilbao (Lange-Valdés, 2018), o el Parque Biblioteca España en Medellín. Estos procesos de regeneración usualmente son gestionados por asociaciones público-privadas (Pastak y Kährik, 2016). Por otra parte, están las estrategias relacionadas a las industrias culturales o creativas (Landry, 2003; Montgomery, 2003; Evans y Shaw, 2004), las cuales a partir de la concentración de actividades relacionadas a la industria cultural, creativa y artística generan distritos culturales, surgiendo desde iniciativas top-down respaldadas en política pública o de manera espontánea a partir de procesos bottom-up. Como ejemplo está la concentración de artistas que se dio en el Poblenou en los 90 (Martí-Costa y Pradel i Miquel, 2011), o el que se ha dado recientemente a partir del movimiento chicano en el Barrio Logan en San Diego [California], Estados Unidos. Por otro lado, también están las estrategias basadas en políticas culturales (Bianchini y Parkinson, 1993; Landry y Bianchini, 1995), cuyo objetivo consiste en apoyar y respaldar procesos de regeneración urbana existentes con la inclusión de agendas culturales que contengan eventos, exposiciones, conciertos y festivales (Duque Franco, 2015). Es el caso del Plan Maestro de Equipamientos Culturales (PLAMEC) en Bogotá.

El desarrollo y gestión para implementar procesos y estrategias culturales en lo urbano van desde la renovación urbana, la cultura y la creatividad (Zukin, 1987; Harvey, 1989; Bianchini y Parkinson, 1993; Landry, 2000), hasta aquellas dirigidas por macro-eventos o proyectos emblemáticos (García, 2004; Shin, 2010; Tallon, 2013; Jung et al., 2015), produciéndose a partir de iniciativas top-down y bottom-up. El modelo topdown consiste en la coordinación de inversión del capital — ya sea público o privado- ajustándose a un plan maestro o de reforma urbana (Tallon, 2013), como los vinculados al distrito 22@ en Barcelona (García et al., 2016). Mientras que el modelo bottom-up se produce a partir de la iniciativa de residentes locales, quienes son los que se encargan de producir, crear y gestionar lo relacionado al proyecto, como lo que sucede en el barrio de Savamala en Serbia (Lazarevič et al., 2016). Por otro lado, están las iniciativas que se producen a partir de asociaciones entre actores (público, privado, civil), las cuales permiten trabajos más colaborativos y transversales, siendo un buen ejemplo la restauración de la fábrica harinera en Zaragoza como equipamiento cultural auto gestionado (Harinera ZGZ) que ha logrado funcionar en base a asociaciones entre sector público y civil. Como vemos, los procesos y estrategias que utilizan la cultura como instrumento para crear y promover regeneraciones urbanas se componen de una diversidad de estrategias y ámbitos de intervención aplicables a escalas muy distintas, por lo que es de esperarse que cada una genere resultados distintos. De esta forma, conocer la percepción de residentes locales puede contribuir en comprender el efecto que cada estrategia de regeneraciones genera, partiendo de un punto de vista local.

Si bien aproximarse a los procesos de regeneraciones urbanas desde la cultura contribuyen al análisis urbanístico (Montgomery, 2004; García, 2004; Evans, 2005; Miles, 2005; Degen y García, 2012; Rius y Posso, 2016) es necesario partir de valoraciones de actores locales para conocer los impactos generados. Por lo tanto, uno de los intereses de esta investigación es visibilizar -a partir de narrativas de informantes clave- la percepción sobre los procesos de regeneración urbana y el papel que la cultura juega como motor de desarrollo urbano. 


\section{La regeneración urbana en el centro de Monterrey, México.}

El centro de Monterrey se compone de un área de 1.111 hectáreas en las que habitan alrededor de 30.000 habitantes. Estos representan el 2,5\% de la población habitante en Monterrey y el 0,63\% de los habitantes del AMM (Figuras 1 y 2). La densidad de población del centro es de 27 hab/ha y cuenta con 1.502

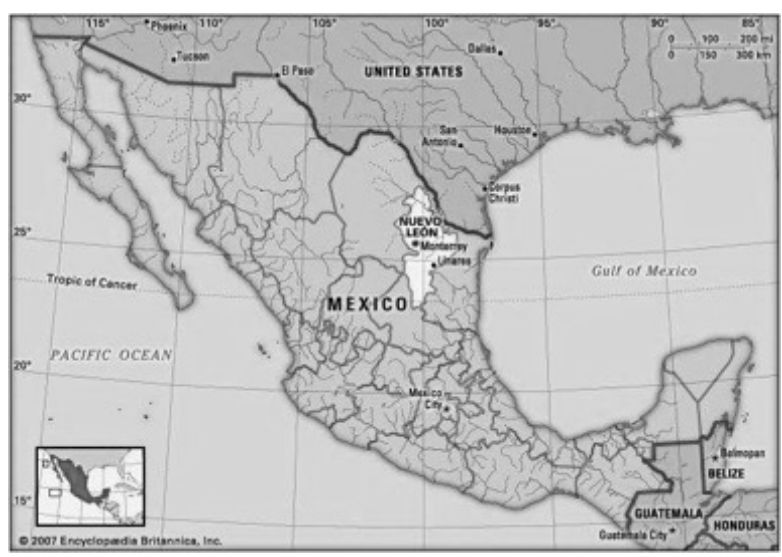

Figura 1. Localización de la ciudad de Monterrey en México. Fuente: Encyclopedia Britannica.

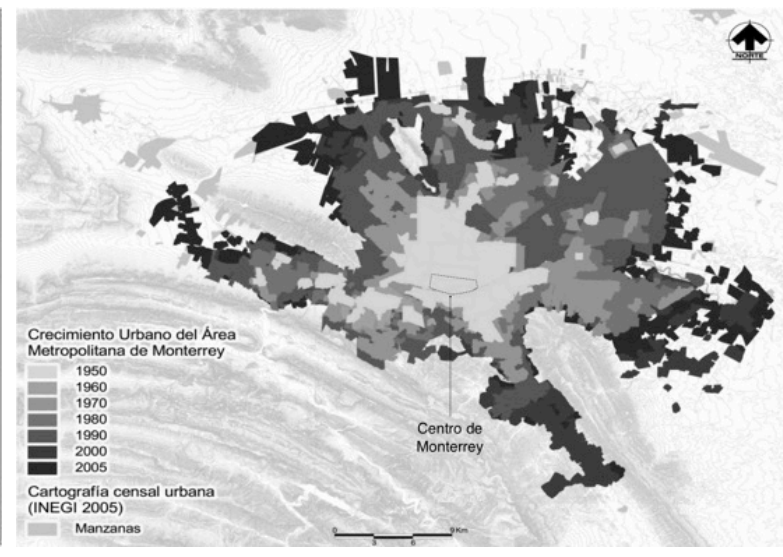

Figura 2. Área metropolitana de Monterrey identificando el centro. Fuente: Elaborado por Edi Morales (intervenida por la autora).

viviendas en estado de abandono1. Ésta situación requiere de un acercamiento y análisis a los proyectos de regeneración urbana implementados (Figura 3) para identificar cómo es que la cultura se vuelve un elemento clave en mejorar su imagen urbana y por tanto, la calidad de vida de sus habitantes. Para resolver estas cuestiones, se parte de diferentes discursos que plantean estrategias y visiones contrapuestas. Estas

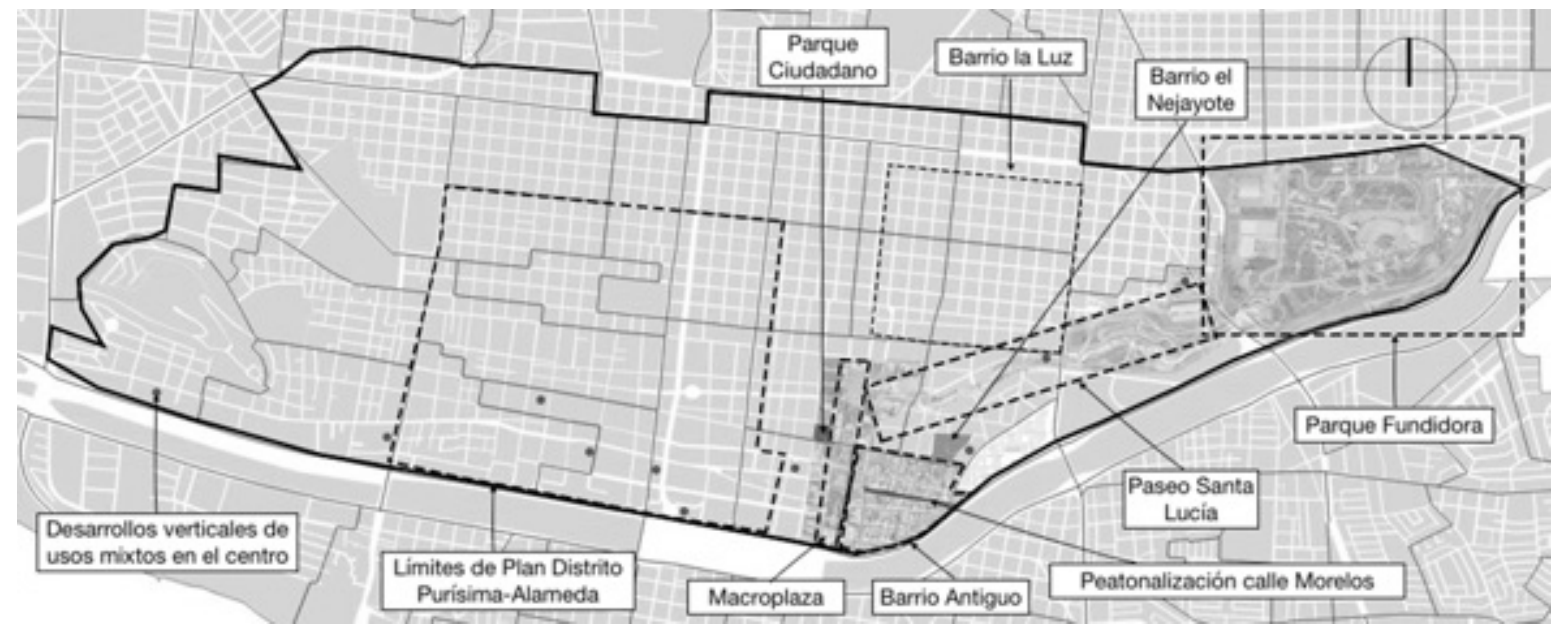

Figura 3. Regeneraciones urbanas realizadas en el centro de Monterrey. Fuente: Elaborado por Fabiola Garza-Rodríguez.

visiones desde el territorio, sirven para contrastar la literatura académica y contextualizar las actuaciones en la realidad mexicana sobre el papel y contribución de las regeneraciones urbanas dirigidas por la cultura. En un recuento por contextualizar las regeneraciones implementadas, mencionar que las propuestas por el sector público-privado han introducido estrategias a partir de la creación de proyectos emblemáticos para atraer inversión en la zona. Las regeneraciones siguientes se enfocan en mejorar la imagen urbana de zonas muy específicas de la ciudad, mientras que de manera paralela surgen proyectos de regeneración propuestos por residentes locales que están cambiando las formas de intervenir el centro.

\subsection{INICIOS DE REGENERACIÓN: LA APUESTA HACIA PROYECTOS EMBLEMÁTICOS (1980-2010)}

La primer etapa inicia en la década de los 80, la cual Prieto (2011) define como la del "Monterrey posmoderno", enfocadas en la creación de proyectos emblemáticos "con más sentido estético que funcional" (Prieto, 2011:171)

${ }^{1}$ Según un estudio realizado por dependencias del sector publico municipal. No se tiene acceso al estudio pero en diversas ocasiones se ha hecho referencia a el a través de notas de prensa como por ejemplo aquí: http://www.elhorizonte.mx/local/en-el-abandono-edificios-del-centro-regio/ 799061 
basadas en la creación de espacio público, equipamientos culturales y recuperación de patrimonio industrial implementados desde un modelo de intervención top-down.

El primer proyecto de regeneración urbana es la Macroplaza. Inaugurada en 1984, para su construcción fue necesario derrumbar cerca de 40 hectáreas del tejido más antiguo de la ciudad (Prieto, 2011). El proyecto parte de una estrategia urbanística pública para impulsar la inversión privada y convertir la zona en centro de negocios (Prieto, 2011) (ver Figuras 4 y 5). Se decía que la zona estaba en abandono y degrado, por lo que era necesario intervenir a través de un proyecto radical de regeneración, sin embargo, hay argumentos que indican que en la zona había actividad comercial, residencial y recreativa (Melé, 2006) con presencia de "edificios de interés

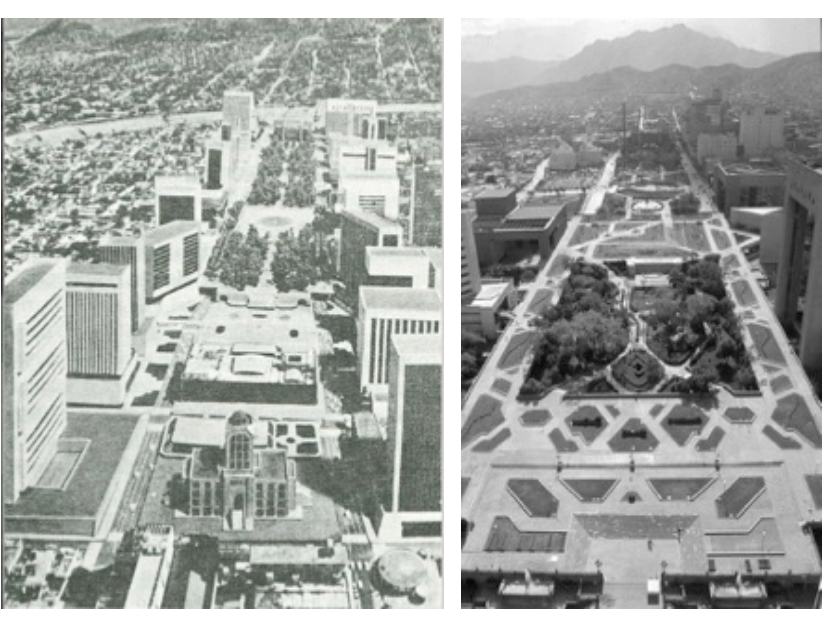

Figuras 4 y 5. Maqueta sobre como se vería la Macroplaza convertida en el nodo financiero propuesto e Macroplaza al 2009 (vista de norte a sur). Fuente: Fermín Téllez e Turismo Nuevo León. bistórico y artístico" (Prieto, 2011:172).

La iniciativa bajo la que se proyecta es top-down (Leal Iga y Fitch Osuna, 2012). Los planes iniciales de convertir la zona en un distrito de negocios no prosperan ya que de manera paralela se proyecta un distrito financiero en otra zona del área metropolitana resultando más atractiva para los inversores (Prieto, 2011). Durante los años siguientes se continúan desarrollando proyectos como equipamientos culturales, monumentos históricos y espacios religiosos, los cuales le han dado un cierto valor cultural a la zona en los alrededores de la Macroplaza, convirtiéndose con el paso de los años en un símbolo de la escena comercial y cultural de la ciudad. Sin embargo, la falta de consolidación como distrito financiero junto con la imposición del sector público por sumarse al movimiento global de desarrollo urbano, aunado a la falta de generar soluciones orientadas a satisfacer necesidades de residentes locales creó más fracturas que coaliciones. El discurso alrededor de la Macroplaza ha ido cambiando con el paso de los años. Si bien en años posteriores a su inauguración el descontento era evidente por la destrucción que supuso y por no generar los objetivos proyectados, hoy en día la valoración se considera positiva por ser el espacio público más importante del centro.

La regeneración del Barrio Antiguo es el proyecto que siguió a la Macroplaza. Éste es conocido oficialmente como el centro histórico de la ciudad (Salgado Gómez, 2006; Prieto González, 2011). A finales de los años 80 el área está en degrado, pero por sus características urbanas e históricas —es el tejido mas antiguo de la ciudad conteniendo ejemplares arquitectónicos que datan del siglo XVIII - se vuelve inminente su intervención. El proyecto de regeneración (1989-1994), tuvo una duración de 5 años y consistió en realzar la estética de un barrio tradicional mediante el desarrollo de industrias culturales, de ocio y entretenimiento (Salgado Gómez, 2006; Prieto González, 2016), concentrando equipamientos culturales de iniciativa privada (flagship projects) como el Museo de Arte Contemporáneo (MARCO). Como parte de la regeneración, se redacta un documento legislativo de protección al patrimonio: la Ley de Patrimonio Cultural del Estado de Nuevo León, la cual entra en vigor a finales de 1991, mientras que en 1993 se declara al Barrio Antiguo como zona protegida con carácter de centro histórico. Su financiamiento se produce desde los 3 niveles de gobierno: federal, estatal y municipal, desarrollándose de manera deductiva (top-down). Aunque aún está vigente la legislación que protege el patrimonio cultural en el barrio, ésta no ha sido aplicada de manera adecuada, ya que inversores privados han intervenido inmuebles catalogados para convertirlos en bares y discotecas sin que hasta ahora haya habido consecuencias legales.

Otro proyecto emblemático es el Paseo Santa Lucía. En 1996 se finaliza su primer etapa, intervención que incluye la construcción del Museo de Historia Mexicana, la Plaza 400 años y el Paseo de Lanchitas (Ovalle, 2007). Además del equipamiento cultural, el proyecto crea espacio público con la plaza y espacios de recreación como el paseo que asemeja un estanque para pasear en lancha. Desde un inicio la idea era conectar el museo con el Parque Fundidora, espacio público que de manera paralela se encontraba en regeneración, sin embargo el proyecto de conexión queda parado durante 9 años. En el 2005 se retoma como excusa para realizar un plan de regeneración para atraer inversión privada, el cual además concuerda con la preparación para acoger el mega-evento Fórum Universal de las Culturas que tendría lugar en el 2007 en la ciudad. Esta segunda fase del proyecto, desarrollada del 2005-2007, une una distancia de 2,5 kilómetros (Macroplaza-Parque Fundidora) a través de un canal artificial de agua que conecta de manera 
peatonal y recreativa dos espacios públicos en el centro. La creación del Paseo Santa Lucía ha impulsado la inversión privada en los alrededores de la zona, en donde se han desarrollado proyectos de iniciativa privada de usos mixtos que contienen residencias, oficinas y comercio (Figura 6).

Los vestigios de la antigua Fundidora de Fierro y Acero se ubican al noreste del centro. La fábrica de fundición fue una de las más importantes de América Latina. A su cierre, en 1988 queda como evidencia la magnitud de su legado en un terreno de 231 hectáreas. $\mathrm{Al}$ poco tiempo de su cierre se ceden los terrenos al sector público para convertirlo en un parque. El plan de regeneración de la Fundidora, llevado bajo una iniciativa top-down desprende una serie de intervenciones urbanas en colaboración con el sector privado con la intención de incrementar la oferta turística, cultural, de ocio y recreación en el polígono y las zonas aledañas. Estas intervenciones se materializan con la construcción de un centro de negocios y un parque de beisbol infantil en terrenos aledaños junto con la restauración de antiguas edificaciones ubicadas dentro del polígono y la reconversión de naves industriales en centros de arte. Como parte de la regeneración de la zona también se construyen salas de conciertos, un hotel 5 estrellas, un parque de diversiones infantil y un teatro al aire libre. La apertura del Parque se da en 2001 declarándose museo de Sitio de Arqueología Industrial. En el periodo 2003-2009 la administración estatal construye la segunda fase del proyecto, en donde se agregan 28 hectáreas más de zonas recreativas (pista de hielo, embarcadero y áreas de esparcimiento), culturales (museos, centro

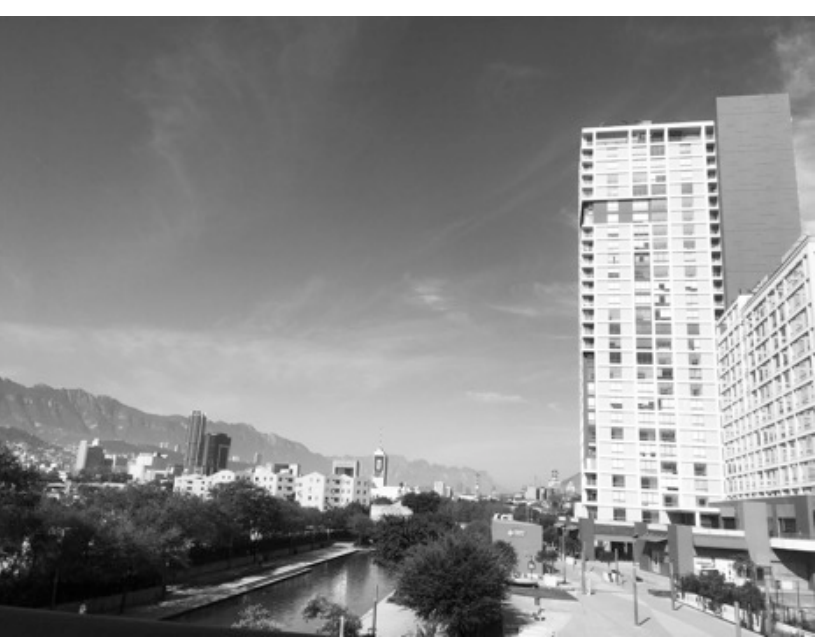

Figura 6. Paseo Santa Lucía con desarrollos inmobiliarios alrededor. Fuente: Fotografía por Fabiola Garza-Rodríguez (enero 2018).

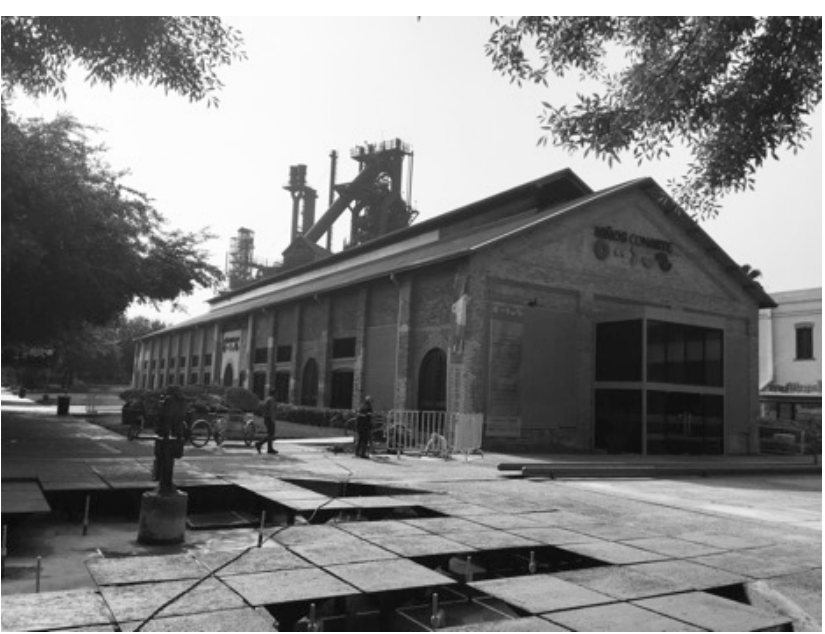

Figura 7. Naves industriales convertidas en equipamiento cultural. Al fondo, la antigua fábrica Fundidora convertida en Museo de Horno y Acero (Horno3). Fuente: Fotografía por Fabiola Garza-Rodríguez (abril 2018). de exposiciones, ver Figura 7) y de servicio (macro-estacionamiento).

\subsection{NUEVAS FORMAS DE REGENERAR EL TERRITORIO: PROYECTOS DE ESCALA LOCAL (2013-ACTUALIDAD)}

La segunda etapa de regeneración urbana identificada, surge a partir del 2013 y se caracteriza por regeneraciones urbanas propuestas por el sector público y por la sociedad civil, las cuales tienen la característica de ser intervenciones más puntuales en el territorio. Las regeneraciones propuestas por el sector público han seguido el modelo de intervención top-down, mientras que las creadas por sociedad civil se basan en modelos bottom-up.

La peatonalización de la calle Morelos en Barrio Antiguo es un proyecto realizado por el sector público municipal junto con la participación de vecinos. La justificación es impulsar la vocación cultural e histórica del barrio a partir de la conversión peatonal de una de sus calles principales. El proyecto se inaugura a finales del 2014 y la regeneración consiste en mejoras estéticas como: nivelación de calle, ampliación de aceras, instalación de bolardos y arborización de especies nativas además de la peatonalización de la calle (Figura 8). También se aplica como Zona 30, velocidad de $30 \mathrm{~km} / \mathrm{h}$, y se crean bahías de ascenso y descenso para negocios locales y el acceso a internet de manera gratuita.

Otro proyecto del sector público en fase de planeación y consulta pública es el plan distrito PurísimaAlameda. El proyecto pretende a través de asociaciones entre actores del sector público, privado, académico y civil revitalizar el distrito mediante el desarrollo de áreas comerciales, habitacionales y de servicios para fomentar inversiones en la zona. Años antes y ajeno al plan, el sector privado ha desarrollado proyectos de redensificación en la zona a través de la construcción de edificios verticales y de usos mixtos. Si bien, estos 
edificios se proyectaron antes de la existencia del plan, se han integrado a él por estar ya presentes. Esto ha motivado al sector privado a impulsar y apoyar la consolidación del plan.

Bajo un esquema distinto se están dando otras regeneraciones en el centro. Esto es a partir de intervenciones bottom-up, proyectos como el que se da en el Barrio del Nejayote, polígono que limita con el Barrio Antiguo. Durante años se conocía como el foco de delito y criminalidad del centro, proyectando imagen de inseguridad y degrado socio-urbano. A partir del 2013 y preocupados por la situación, un grupo de residentes locales con vocación y profesión artística, crean el colectivo y proyecto "Caminando en mi Barrio", el cual consiste en rehabilitar y mejorar de manera estética las aceras del barrio, a partir de imágenes que representen la identidad de la ciudad realizadas con pedazos de mosaicos de colores, una técnica conocida como trencadís (Figura 9). Artistas junto con vecinos diseñan, financian y 'construyen' las aceras intervenidas. El uso y apropiación de las aceras no está regulado por el sector público, quedando un vacío legislativo, por lo tanto la regeneración se ha ejercido sin limitaciones. El material utilizado proviene de donaciones y en ocasiones por medios económicos del propietario de la acera por regenerar. El proyecto ha crecido al grado de que también realizan actividades culturales en el barrio como festivales de música, bazares y talleres artísticos que atraen tanto a ciudadanos de toda el área metropolitana como a visitantes extranjeros de la ciudad.

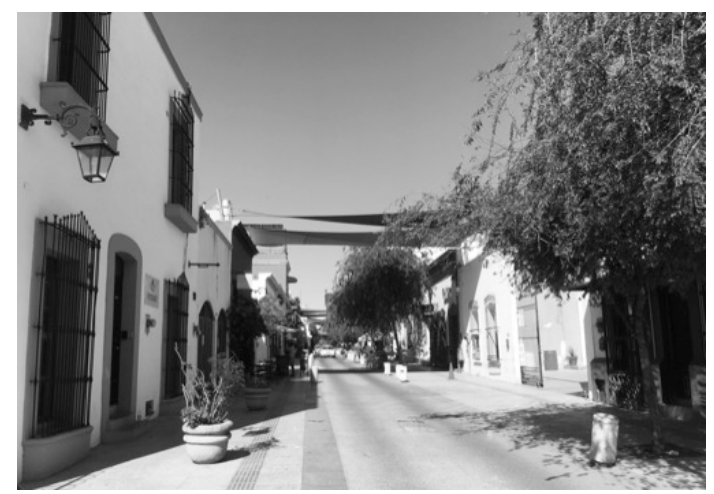

Figura 8. Peatonalización de calle Morelos en Barrio Antiguo. Fuente: Fotografía por Fabiola Garza-Rodríguez (abril 2018).

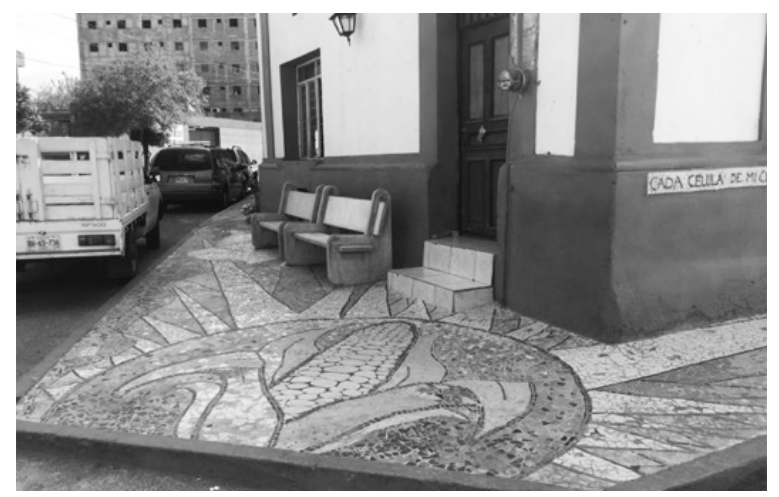

Figura 9. Intervención en Barrio el Nejayote por el colectivo 'Caminando en mi Barrio'. Fuente: Animal Político.

Barrio La Luz Cultura Viva, es un grupo formado por vecinos que habitan en el Barrio de la Luz, ubicado al noreste del centro y el cual es históricamente conocido como el barrio de artes y oficios del Monterrey antiguo. En 2013, en un intento por devolverle su identidad, se comienzan a instalar artistas, talleres, espacios y cafés culturales. Así nace el grupo de vecinos y colectivo Barrio la Luz, Cultura Viva, como un grupo vecinal conformado por artistas, artesanos y vecinos que habitan el barrio. El colectivo ha generado una serie de proyectos que van desde festivales, actividades y manifestaciones culturales que promueven la identidad del barrio, el sentido de pertenencia y la cohesión social entre vecinos. En 2017, la institución cultural del sector público, el Consejo para la Cultura y las Artes de Nuevo León (CONARTE), les otorga una beca económica con duración de seis meses para que continúen desarrollando actividades culturales en el barrio. Este es un ejemplo de cómo una iniciativa bottom-up logra el apoyo de la esfera pública para un bien común, algo histórico en la ciudad de Monterrey.

Parque Ciudadano es otra regeneración que se da desde iniciativa bottom-up. Surge a finales del 2014 gracias a que ciudadanos logran detener el inicio de obra de un estacionamiento para trabajadores del sector público, el cual se proyecta en una de las pocas áreas verdes existentes en el centro. La falta de áreas verdes, junto al valor ecológico del solar por tener más de 30 árboles de la región, fueron motivo suficiente para que los ciudadanos con el apoyo del sector académico se manifiesten en contra de la obra argumentando que en lugar del estacionamiento podría proyectarse un espacio público. Los ciudadanos 'okupan' el solar durante 14 días ininterrumpidos en uno de los inviernos más crudos de la ciudad. La presión ciudadana, tanto presencial como a través de redes sociales, logra que el sector público detenga la construcción. Las negociaciones ciudadanas para que el solar se convierta en un parque duran más de dos años. Años en los cuales, la ciudadanía utiliza el área como espacio público, organizándose para llevar a cabo acciones de limpieza y mantenimiento. Durante el tiempo de negociación se convoca a concurso público el diseño del parque. Es a finales del 2017 cuando el sector público ya con el proyecto ganador, comienza la construcción del parque. Para construirlo, se utiliza el 1\% del presupuesto asignado para el estacionamiento. En abril de 2018 el Parque Ciudadano ha sido finalmente inaugurado (Figura 10). 


\section{Análisis de narrativas en torno al centro}

A continuación se analizan las entrevistas realizadas a actores clave para obtener las valoraciones generadas en torno a los procesos de regeneración urbana implementados y las formas en que la cultura esta siendo elemento de regeneración en el centro.

\subsection{LAS PROBLEMÁTICAS URBANAS Y SU ORIGEN}

Uno de los principales problemas del centro es su abandono. Un factor importante y posible explicación a este fenómeno es la situación legal de los inmuebles, que al quedar intestados entran en un ciclo de procesos legales largos y costosos, provocando su abandono (Figura 11) por el vacío legal en el que se encuentra. El centro es visto como un

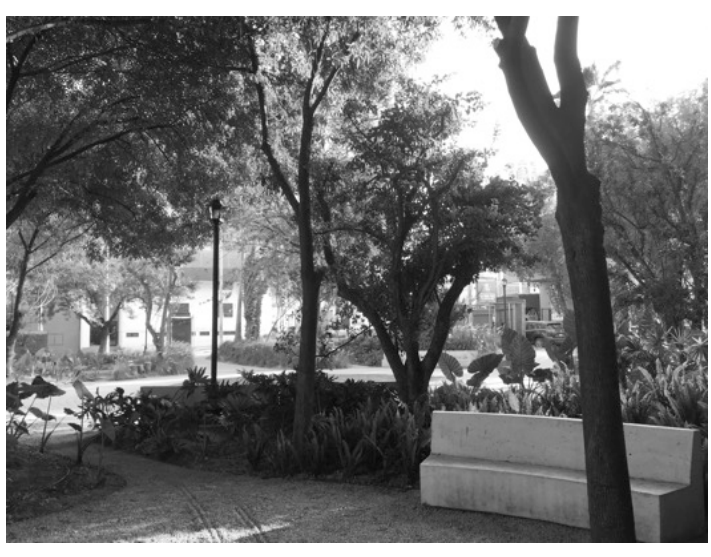

Figura 10. Parque Ciudadano recién inaugurado. Fuente: Fotografía por Fabiola Garza-Rodríguez (abril 2018). lugar no habitable. En contraste, se aprecia que el proble-

ma es de percepción y no realmente de abandono. Activistas e investigadores concuerdan en que sí, hay zonas abandonadas, pero argumentan que este fenómeno no es generalizado ni extrapolable a todo el centro. Defienden que esta percepción se debe a la falta de mantenimiento urbano por parte del sector público por no mantener en buenas condiciones la imagen urbana y la infraestructura. Otras problemáticas percibidas son la falta de equipamientos públicos, culturales, espacios de recreación, áreas verdes y servicios básicos. La ausencia de complejidad urbana se percibe como limitante para la constitución de un centro compacto, accesible y cohesionado siendo esta variable la causa que frena dinámicas que promuevan su calidad urbana.

"El centro tiene muchos problemas, claramente es urbano, también de infraestructura y desaprovechamiento de zonas, carencia de áreas verdes [...] todos esos son lugares comunes” (Investigador).

Las causas y responsabilidad de las problemáticas recaen en el sector público (administración municipal y estatal) y privado, por ser los responsables de crear políticas de mantenimiento y estrategias de mejora que tienden a favorecer la especulación urbanística. Ésta se manifiesta con la compra/venta de terrenos o inmuebles en mal estado para después obtener mayores beneficios económicos con su venta. Este fenómeno es visto en predios, viviendas y locales que están abandonados y por los cuales se piden grandes cantidades monetarias.

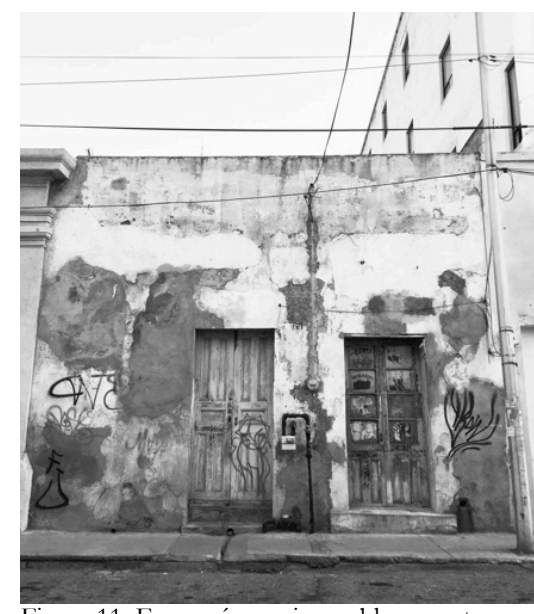

Figura 11. Es común ver inmuebles en estas condiciones de degrado y abandono en el centro. Fotografía por Fabiola Garza-Rodríguez (abril 2018).

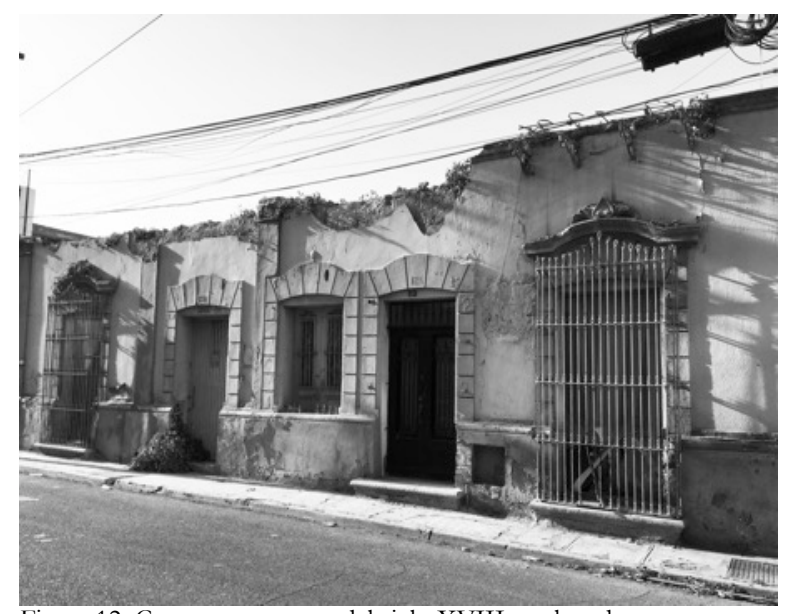

Figura 12. Casona norestense del siglo XVIII catalogada como patrimonio arquitectónico en el centro a medio derruir. Fotografía por Fabiola Garza-Rodríguez (diciembre 2017).

El sector público apuesta por la redensificación apoyando con políticas y cambios de uso de suelo al sector privado para la construcción de edificios verticales de usos mixtos, pero la falta de políticas públicas urbanas y de incentivos que permitan el acceso a la vivienda son factores que frenan la ocupación de estas edificaciones, las cuales se orientan a población con alto nivel de renta. La destrucción del patrimonio arquitectónico es una problemática generalizada en el centro. En el tejido urbano existen ejemplares arquitectónicos con alto valor patrimonial, inmuebles que datan del siglo XVIII, XIX y principios del XX, además de edificios representativos del movimiento moderno y art decó. La falta de conocimiento del valor patrimonial por 
parte de los dueños de los inmuebles es la mayor amenaza contra la historia y memoria de la ciudad, ya que atenta contra su preservación, eliminando de manera arbitraria su pasado urbano (Figura 12).

\title{
4.2. LAS ACTUACIONES URBANÍSTICAS
}

Investigadores y activistas declaran que las actuaciones de los actores públicos y privados hacia regenerar el centro es nula, ya que los proyectos generados se basan en cumplimentar estrategias globales de regeneración con fuerte sentido económico y no en regenerar a partir de necesidades locales. En contraparte, el discurso del sector público manifiesta de manera constante en artículos de prensa que están en proceso proyectos de regeneración (como ejemplo el Plan del Distrito Purísima-Alameda, publicado a finales del 2017). Por lo que no se puede decir que el sector público no tiene planes de intervención, solo que como todo proyecto en fases iniciales, aún no es visible. El argumento por parte del sector público se manifiesta en el siguiente extracto de una entrevista radiofónica realizada a finales del 2017:

\begin{abstract}
"Estamos enfocados en darle mayor calidad de vida al peatón en el centro de Monterrey, esto es mejorar las banquetas, mejorar la escala bumana de la ciudad [...] Para el centro la visión es recuperar el espacio público. Sentimos que si el espacio público es de calidad vendrá la inversión y entonces vendrán todas esas obras nuevas, esa es nuestra apuesta, crear más espacio público y en paralelo una visión metropolitana” (Representante de administración pública municipal).
\end{abstract}

La postura de los arquitectos sobre los proyectos de regeneración urbana realizados por el sector público como la Macroplaza, la regeneración del Barrio Antiguo, el Parque Fundidora, el Paseo Santa Lucía y la peatonalización de la calle Morelos, es que se realizan de manera impositiva, además de que no cuentan con programas de participación ciudadana integradas al diseño y gestión del proyecto de regeneración. Los entrevistados concuerdan en que la falta de diálogo y trabajo en conjunto entre actores es la principal limitante para cumplir objetivos de proyectos de regeneración realizados por el sector público y privado.

"No es un problema de que el proyecto este mal planteado, que a veces sí, pero no es el principal. El problema es que no hay negociaciones entre partes, no hay diálogos, no hay mesas de debate, no bay esto" (Arquitecto).

Por el contrario, la percepción es positiva sobre los proyectos de regeneración realizados por residentes locales. Concuerdan en que son casos de éxito por el alcance que han tenido, por su permanencia y por que algunos, como en el caso del grupo del Barrio La Luz Cultura Viva o el proyecto del Parque Ciudadano, han logrado traspasar a la esfera pública, trabajando en conjunto a través de asociaciones entre actores que respaldan y validan las intervenciones, de ahí que logren generar mayores impactos en la percepción local. Este tipo de acciones son relevantes en el contexto regiomontano porque en Monterrey la participación ciudadana es mínima, por lo que el valor más potente de estas intervenciones es el legado de que es posible lograr transformaciones urbanas que surjan desde la iniciativa ciudadana.

"El proyecto del Nejayote es una iniciativa muy especial que embellece al lugar y ha actuado como una bola de nieve beneficiando a los vecinos porque todos quieren unirse y transformar sus aceras [...] Ahora las personas reconocen el barrio y lo asocian inmediatamente con la intervención en las aceras" (Arquitecto).

Estos proyectos están transformando la imagen urbana y la estética del centro a partir de intervenciones puntuales, pero a su vez, su valor agregado es que refuerzan la identidad local y el sentido de pertenencia entre habitantes a través de actividades y manifestaciones culturales que fomentan la cohesión social.

\subsection{POTENCIALIDADES Y PROPUESTAS EN UN CENTRO OLVIDADO}

La mayor parte de los entrevistados reconoce que aunque existe un alto potencial de recursos culturales (espacio público, áreas verdes, patrimonio histórico-arquitectónico, elementos simbólicos y equipamiento cultural), es necesario fomentar su uso y su relación con el entorno urbano a través de estrategias que permitan integrarlos en la vida cotidiana de los habitantes. Los equipamientos culturales se consideran escasos pero de calidad, ya que además de recibir exposiciones internacionales son parte de los proyectos emblemáticos de la ciudad como es el caso del Museo de Arte Contemporáneo (MARCO) o el Museo de Historia Mexicana. La mayoría de los equipamientos culturales del AMM están en el centro, sobre todo en la zona alrededor de la Macroplaza. Esta centralidad se reconoce como la principal desventaja en cuanto a términos de proximidad y accesibilidad para la población. Como complemento, mencionar que solo un organismo gestiona la cultura en el estado: el CONARTE. Por lo tanto, junto a la centralidad geográfica de los equipamientos culturales se suma la centralidad en la creación, distribución y difusión de la cultura. Aunque el CONARTE realiza un buen número de actividades culturales como festivales, presentaciones, 
obras de teatro al aire libre, expresiones artísticas como danza y música, hace falta generar más difusión ya que los entrevistados argumentan que tiende a la exclusividad de los interesados.

"Es medio underground, si hay cosas pero necesitas estar en el medio (cultural). Es la misma gente que se mueve de un lugar a otro y son actividades mas o menos parecidas unas a otras. No hay difusión para gente que no conozca o viva en el centro y a veces hay cuestiones culturales interesantes y la difusión es minima” (Activista).

Sobre el rol de la cultura para regenerar el centro, los entrevistados mencionan que ésta puede manifestarse con actividades relacionadas al arte urbano, a través de la creación de más espacios públicos y mediante diversificación de oferta cultural. Las propuestas se dirigen hacia valores culturales como la estética, mientras que otras apuntan hacia explorar el valor de inspiración que la cultura produce en el tejido social mediante expresiones artísticas o a través de la restauración de inmuebles patrimoniales en abandono para devolverle su importancia arquitectónica con un nuevo uso. Otra propuesta es mediante la ocupación de terrenos vacíos con instalaciones temporales convertidas en espacio público en donde se generen actividades que promuevan la convivencia entre residentes locales. Los entrevistados argumentan que la cultura puede ser la estrategia clave para regenerar el centro porque al fortalecer el sentido de pertenencia es posible generar transformaciones de raíz que trasciendan hacia la esfera público o privada. Como ejemplo, esta lo que sucede en el Barrio del Nejayote o el Barrio de la Luz.

"El rol de la cultura es ayudarnos a reconocernos a nosotros mismos como ciudadanos de un lugar, reconocer que tenemos tradiciones, costumbres, que tenemos sueños más allá de la producción y el consumo" (Investigadora).

\section{Discusión: Hacia una regeneración urbana más colaborativa}

La cultura en el discurso del desarrollo sostenible se ha posicionado en el sector urbano como estrategia para realizar regeneraciones en la era de la globalización (Landry, 2000; García, 2004; Miles, 2005;). El carácter holístico del concepto le permite actuar desde diversos frentes (Plieninger et al., 2015) ya que la cultura se alza como imán para atraer inversiones y ayudar en la reactivación económica de un lugar ayudando a proyectar una nueva imagen de la ciudad tomando como eje central la cultura, la creatividad, las artes, la innovación y las políticas culturales (Montgomery, 2003; Landry, 2003; Evans y Shaw, 2004; Florida, 2005; Bianchini y Ghilardi, 2007). Las regeneraciones urbanas que han tenido lugar en el centro de Monterrey se basan en modelos variados (ver tabla 1). Si bien, en un periodo inicial la mayor parte de ellas se implementan desde procesos y estrategias top-down, en épocas recientes comienzan a afianzarse y consolidarse proyectos desde estrategias bottom-up, propuestas por residentes con el fin de solucionar necesidades locales.

Tabla 1. Elementos comparativos entre procesos de regeneración. Elaboración propia.

\begin{tabular}{|c|c|c|c|}
\hline Periodo & $\begin{array}{c}\text { Procesos / Estrategias de } \\
\text { intervención }\end{array}$ & Gobernanza & Impactos \\
\hline 1980-2010 & $\begin{array}{l}\text { (1) Creación de espacio público } \\
\text { para convertir en nodo de negocios } \\
\text { (2) Regeneración urbana de barrio } \\
\text { antiguo } \\
\text { (3) Creación de río que conecta dos } \\
\text { espacios públicos } \\
\text { (4) Reconversión de antigua fabrica } \\
\text { (5) Creación de proyectos } \\
\text { emblemáticos para el centro }\end{array}$ & $\begin{array}{l}\text { Top-down } \\
\text { A través de } \\
\text { asociaciones } \\
\text { entre sector } \\
\text { publico y } \\
\text { privado }\end{array}$ & $\begin{array}{l}\text { (1) Desplazamiento de población } \\
\text { (2) Mejora escenográfica y aumento de uso de } \\
\text { suelo para bares y restaurantes } \\
\text { (3) Creación de espacio publico, conexiones } \\
\text { urbanas y peatonales } \\
\text { (4) Creación de un parque para la ciudadanía y } \\
\text { de museos de arquitectura industrial } \\
\text { (patrimonio) } \\
\text { (5) Construcción de equipamientos culturales }\end{array}$ \\
\hline $\begin{array}{l}\text { 2013- } \\
\text { actualidad }\end{array}$ & $\begin{array}{l}\text { (1) Intervención en aceras con } \\
\text { técnica artística } \\
\text { (2) Concentración de artistas en un } \\
\text { barrio del centro } \\
\text { (3) Manifestación social en contra } \\
\text { de un estacionamiento }\end{array}$ & $\begin{array}{l}\text { Bottom-up } \\
\text { Asociaciones } \\
\text { entre actores } \\
\text { (Público/civil) }\end{array}$ & $\begin{array}{l}\text { (1) Mejora en la estética y percepción urbana } \\
\text { del barrio } \\
\text { (2) Aumento en cohesión social, sentido de } \\
\text { pertenencia } \\
\text { (3) Creación de espacio público }\end{array}$ \\
\hline
\end{tabular}

Se identifican dos etapas de regeneraciones urbanas que se han realizado en el centro. La primera corresponde al periodo de 1980-2010, la cual llamamos la época de los proyectos emblemáticos por ser proyectos en donde la estrategia cultural se basa en la construcción y reconversión de equipamientos e infraestructura cultural de gran escala urbana para posicionar a la ciudad como una adaptada al contexto de la globalización 
(Prieto, 2011). Es el caso de la Macroplaza y del Paseo Santa Lucía, proyectos que por su escala y por su ámbito de intervención buscan generar impacto internacional en la imagen de la ciudad con la finalidad de atraer turismo e inversiones. En el caso del Barrio Antiguo, la mejora consistió en cambio de texturas en el pavimento y trabajos de reconstrucción y pintura en fachadas pero no lograron grandes transformaciones en el tejido social, provocando por el contrario, desplazamiento entre la mayor parte de sus residentes locales por su reconversión en un barrio con alta actividad nocturna con alta presencia de bares y discotecas. Algo similar sucede en los alrededores de la Macroplaza y el Paseo Santa Lucía, en donde se han edificado desarrollos de usos mixtos que combinan actividad comercial con residencias y oficinas, pero que han tendido al desplazamiento de residentes locales por destinarse a población con alto nivel de renta, comenzando a iniciar procesos de gentrificación. Estos proyectos, desarrollados bajo estrategias top-down manejadas a través de asociaciones entre sector público-privado no son percibidas por los entrevistados como regeneraciones urbanas que hayan logrado grandes transformaciones socio-urbanas. $\mathrm{Si}$ bien, es claro que su magnitud es evidente en el tejido urbano y lo ha transformado de forma estética y visual, no se han conseguido los resultados esperados en cuestiones sociales y culturales, generando más marginación y degradación en lugar de atenuarla. Algo que se ha demostrado en otros contextos que influye en generar estas condiciones (Eizenberg y Cohen, 2014).

Por otra parte el periodo 2013-actualidad se ha caracterizado por el surgimiento de regeneraciones y proyectos a partir de iniciativas bottom-up que han activado procesos e iniciativas culturales y artísticas como respuesta a una necesidad social y sobre todo, local. Su escala de intervención es mucho menor comparada con los proyectos de regeneración urbana que el sector público y privado han realizado, pero han impactado de manera positiva en generar cohesión social en los barrios por el trabajo colaborativo entre colectivos, organizaciones culturales y vecinos. Además, se han generado procesos interesantes de colaboración entre actores como sociedad civil y sector público, como en el caso del Parque Ciudadano. Se ha demostrado que estas condiciones en otros contextos generan cohesión social y promueven la sostenibilidad cultural del lugar (Lazarević et al., 2016).

En el caso del Barrio del Nejayote, el uso de la cultura se manifiesta a partir de la intervención estética de las aceras, empleando un valor estético que fomenta el carácter turístico y cultural del barrio junto con el sentido de pertenencia e identidad del lugar al utilizar imágenes que aluden a la identidad norestense, como por ejemplo, el Cerro de la Silla. Por otra parte en Barrio de La Luz, la cultura se manifiesta a través de la presencia y concentración de artistas que además de generar actividades propias entorno a la cultura, han impulsado la presencia de nuevos espacios culturales como talleres de arte, galerías y cafés culturales los cuales han contribuido en generar actividades en coalición para fortalecer la convivencia y la identidad histórica del barrio. Esto demuestra que la escala de intervención urbana no es trascendental, ya que al menos en este caso de estudio pequeñas transformaciones han logrado mayor visibilidad entre habitantes y ciudadanos que los proyectos realizados por el sector público y privado. En ese sentido, los proyectos de regeneración urbana impulsados desde iniciativas bottom-up contribuyen en fomentar la sostenibilidad cultural por ser realizados desde iniciativas sociales y culturales.

Una forma en la que podemos comprobar que las regeneraciones bottom-up en el centro han generado impactos mayores que las propuestas desde iniciativas top-down es a través de las entrevistas, en donde las valoraciones apuntan a que estos proyectos son reconocidos como los que están transformando la imagen urbana y la percepción social del centro. Resulta interesante que el reconocimiento por parte de los entrevistados sobre las regeneraciones urbanas que han tenido lugar en el centro se orienten hacia las iniciativas ciudadanas en lugar de orientarse hacia las grandes intervenciones propuestas por el sector público-privado, las cuales de manera inicial se creería que son las que generan mayores impactos por su escala y magnitud. En un recuento sobre lo formulado, como propuesta de cara hacia futuras regeneraciones urbanas, se propone la apuesta hacia un modelo conjunto de colaboración entre actores, en donde sociedad civil junto con sector público y privado creen coaliciones y trabajen de manera paralela para generar mayores impactos en los proyectos por realizar. Esto también supone una revisión y mejora en las formas de intervenir el territorio, a partir de procesos de planeación y gestión que tomen otros ámbitos como punto base para realizar regeneraciones urbanas más integrales.

\section{Conclusión}

Este trabajo ha analizado los proyectos de regeneración urbana realizados en el centro de Monterrey para valorar su alcance junto con la valoración cualitativa mediante entrevistas a actores clave. Los resultados muestran que en los últimos 30 años el sector público se ha preocupado por generar proyectos para revitalizar el centro mediante la realización de proyectos emblemáticos que si bien han contribuido a mejorar la imagen urbana de la zona y a crear espacios públicos y culturales necesarios para la ciudadanía siguen realmente sin cumplir la función de convertirlo en un lugar dinámico, complejo y cohesionado. Influye el 
hecho de que no existe comunicación entre actores y dependencias, lo que provoca falta de continuidad y seguimiento en los proyectos.

Por el contrario, los proyectos generados desde iniciativas bottom-up, son los que están generando impactos positivos reflejados en mayor cohesión social y en la creación de actividades culturales y artísticas que contribuyen en la sostenibilidad cultural del centro al fomentar actividades que refuerzan la identidad, la cohesión social y el sentido de pertenencia del lugar. Éstos proyectos están generando cambios efectivos en la percepción ciudadana por lo que se demuestra que la comunidad está regenerando áreas específicas del centro de Monterrey desde procesos bottom-up y que bien gestionados pudieran alcanzar transformaciones integrales a través de asociaciones con el sector público y privado. Si bien, no todas las estrategias culturales son replicables a cualquier entorno urbano, si que es posible a partir del contexto específico del área a regenerar proponer estrategias de intervención basadas en componentes locales.

Es necesario integrar en los proyectos de regeneración urbana más diversidad de estrategias, iniciativas y políticas que vayan desde lo urbano, cultural, económico, social y ambiental, ya que contribuciones más holísticas y colaborativas desde diversos ámbitos pueden provocar mayores impactos que fomenten la sostenibilidad en la ciudad. Dentro de los aportes más significativos de esta investigación se demuestra que los proyectos de regeneración desde iniciativas bottom-up logran consolidarse gracias a la sinergia generada entre sector público y sociedad civil. Por lo que es necesario fomentar sinergia entre actores. Para generar cambios e impactos significativos y perdurables es necesario trabajar en conjunto y respaldarse entre actores, ya que todas las acciones por mejorar los entornos donde vivimos forman parte de un bien común, imposible de alcanzar sin estas colaboraciones.

\section{Referências}

Bayliss, D. (2004). Creative planning in Ireland: the role of culture-led development in Irish planning. European Planning Studies, 12, 497-515. Recuperado de: <https://doi.org/10.1080/0965431042000212759>.

Bianchini, F. y Parkinson, M. (eds.) (1993). Cultural Policy and Urban Regeneration: The West European Experience. Manchester: Manchester University Press.

Bianchini, F. y Ghilardi, L. (2007). Thinking culturally about place. Place Branding and Public Diplomacy, 3(4), 280-286. Recuperado de: <https://doi.org/10.1057/palgrave.pb.6000077>.

Blessi, G.; Tremblay, D.; Sandri, M.; Pilati, T. (2012). New trajectories in urban regeneration processes: Cultural capital as source of human and social capital accumulation - Evidence from the case of Tohu in Montreal. Cities, 29, 397-407. Recuperado de: <https://doi.org/10.1016/j.cities.2011.12.001>.

Castells, M. (1991). «El auge de la ciudad dual: teoría social y tendencias sociales». Alfoz, (80), 89-103.

Degen, M. y García, M. (2012). The transformation of the 'Barcelona model': an analysis of culture, urban regeneration and governance. International journal of urban and regional research, 36(5), 1022-1038. Recuperado de: $<$ https://doi.org/10.1111/j.1468-2427.2012.01152.x>.

Dinardi, C. (2012). Unsettling the role of culture as panacea: the politics of culture-led urban regeneration In Buenos Aires. City, Culture and Society, 6(2), 9-18. Recuperado de: <https://doi.org/10.1016/j.ccs.2015.03.003>.

Duque Franco, I. (2015). La cultura como estrategia de transformación y promoción urbana en Bogotá y Medellín. Revista de Geografia Norte Grande, (61), 25-43. Recuperado de: <http://dx.doi.org/10.4067/S0718-34022015000200003>.

Eizenberg, E. y Cohen, N. (2015). Reconstructing urban image through cultural flagship events: The case of BatYam. Cities, 42, 54-62. Recuperado de:<https://doi.org/10.1016/j.cities.2014.09.003>.

Evans, G. y Shaw, P. (2004). The contribution of culture to regeneration in the UK: a review of evidence. London: DCMS, 4.

Evans, G. (2005). Measure for measure: Evaluating the evidence of culture's contribution to regeneration. Urban Studies, 42(5-6), 959-983. Recuperado de: <DOI: 10.1080=00420980500107102>.

Florida, R. (2005). Cities and the Creative Class. Nueva York y Londres: Routledge.

García, B. (2004). Cultural policy and urban regeneration in Western European cities: lessons from experience, prospects for the future. Local economy, 19(4), 312-326. Recuperado de: <DOI: 10.1080/0269094042000286828>. 
García, A.; Fernández, V.; Caravaca, I.; González, G. (2016). Actividades creativas, transformaciones urbanas y paisajes emergentes. El caso del casco norte de Sevilla. Documents d'Anàlisi Geogräfica, 62(1), 27-54. Recuperado de: <http://dx.doi.org/10.5565/rev/dag.245>.

Harvey, D. (1989). From Managerialism to Entrepreneurialism - the Transformation in Urban Governance in Late Capitalism. Geografiska Annaler Series B-Human Geography, 71, 3-17.

Heath, S.; Rabinovich, A. y Barreto, M. (2017). Putting identity into the community: exploring the social dynamics of urban regeneration. European Journal of Social Psychology, 47, 855-866. Recuperado de: <http://dx.doi.org/10.1002/ ejsp.2296>.

Jones, P. y Evans, J. (2008). Urban regeneration in the UK: Theory and Practice. London: SAGE. Recuperado de: <http:// dx.doi.org/10.4135/9781473915015>.

Jung, T. H.; Lee, J.; Yap, M., H.T. y Ineson, E. M. (2015). The role of stakeholder collaboration in culture-led urban regeneration: A case study of the Gwangju Project, Korea». Cities (44), 29-39. Recuperado de: <https://doi.org/ 10.1016/j.cities.2014.12.003>.

Kana, K. (2012). An experiment in urban regeneration using culture and art in Senba, Osaka's historic urban center, with a focus on the regeneration of urban space. City, Culture and Society, 3, 151-163. Recuperado de: <http:// doi.org/10.1016.j.ccs.2012.06.006>.

Kanai, M. y Ortega-Alcázar, I. (2009). The Prospects for Progressive Culture-led urban regeneration in Latin America: Cases from Mexico City and Buenos Aires. International Journal of Urban and Regional Research, 33(2), $483-501$. Recuperado de: <https://doi.org/10.1111/j.1468-2427.2009.00865.x>.

Landry, C. y Bianchini, F. (1995). The creative city. Londres: Demos. Recuperado de: <http://www.demos.co.uk/files/ thecreativecity.pdf $>$.

Landry, C. (2000). The creative city: A Toolkit for Urban Innovators. London: Earthscan.

Landry, C. (2003). Imagination and regeneration: Cultural policy and the future of cities. Cultural Policy and Action Department, Directorate General IV, Council of Europe.

Lange-Valdés, C. (2018). La arquitectura como dispositivo de regeneración urbana: 20 años del Museo Guggenheim Bilbao. Bitácora Urbano Territorial, 28(2), 115-123. Recuperado de: <https://doi.org/10.15446/bitacora.v28n2.70153>.

Lazarević, E. V.; Koružnjak, A. B. y Devetaković, M. (2016). Culture design-led regeneration as a tool used to regenerate deprived areas. Belgrade-The Savamala quarter; reflections on an unplanned cultural zone. Energy and Buildings, 115 (3-10). Recuperado de: <http://dx.doi.org/10.1016/j.enbuild.2015.03.015>.

Leal Iga, C. y Fitch Osuna, J. M. (2012). Políticas urbanas. Tendencia de transformación en el área de influencia de grandes proyectos. Contexto. Revista de la Facultad de Arquitectura de la Universidad Autónoma de Nuevo León, 6(6).

Martí-Costa, M. y Pradel I Miquel, M. (2011). The knowledge city against urban creativity? Artists' workshops and urban regeneration in Barcelona. European Urban and Regional Studies, 19(1), 92-108. Recuperado de: <DOI: 10.1177/0969776411422481>.

Melé, P. (2006). La producción del patrimonio urbano. Centro de Investigaciones y Estudios Superiores en Antropología Social: México.

Miles, M. (2005). Interruptions: Testing the rhetoric of culturally led urban development. Urban Studies, 42(5-6), 889-911. Recuperado de: <DOI: 10.1080/00420980500107375>.

Montgomery, J. (2003). Cultural quarters as mechanisms for urban regeneration. Part 1: Conceptualising cultural quarters. Planning, Practice \& Research, 18(4), 293-306. Recuperado de: <https://doi.org/ $10.1080 / 1561426042000215614>$.

Montgomery, J. (2004). Cultural quarters as mechanisms for urban regeneration. Part 2: A review of four cultural quarters in the UK, Ireland and Australia. Planning, Practice \& Research, 19(1), 3-31. Recuperado de: <https://doi.org/ 10.1080/0269745042000246559>.

Ovalle, M. (2007). El último vestigio del molino "El Hércules", en Monterrey, Nuevo León. Boletín de Monumentos Históricos, (10), 56-70. 
Pastak, I y Kährik, A (2016). The impacts of culture-led flagship projects on local communities in the context of post-socialist Tallin. Sociologicky Casopis, 52(6), 963. Recuperado de: <https://doi.org/ 10.12060/00380288.2016.52.6.292>.

Pethia, S. R. (2011). Reconstructing communities: The impact of regeneration on community dynamics and processes. (Doctoral dissertation, University of Birmingham).

Plieninger, T.; Bieling, C.; Fagerholm, N. et al (2015). The role of cultural ecosystem services in landscape management and planning». Current Opinion in Environmental Sustainability 14, 28-33. Recuperado de: <https:// doi.org/10.1016/j.cosust.2015.02.006>.

Pratt, A. C. (2009). Urban regeneration: From the arts 'feel good' factor to the cultural economy: A case study of Hoxton, London». Urban Studies, 46(5-6), 1041-1061. Recuperado de: <https://doi.org/ 10.1080/02697459108722794>.

Prieto, J. M. (2011). La consolidación del Monterrey imaginario en el contexto de la globalización: Macroproyectos urbanos. Frontera norte, 23(45), 163-191.

Rius, J. y Posso, L. (2016). Cultura, transformación urbana y empoderamiento ciudadano frente a la gentrificación. Comparación entre el caso de Getsemaní (Cartagena de Indias) y el Raval (Barcelona). EURE (Santiago), 42(126), 97-122. Recuperado de: <http://dx.doi.org/10.4067/S0250-71612016000200005>.

Roberts, P.; Sykes, H.; Granger, R. (eds.) (2016). Urban Regeneration. London: SAGE. Recuperado de: <http:// dx.doi.org/10.4135/9781473921788.n1>.

Salgado Gómez, A. (2006). El Barrio Antiguo de Monterrey: ¿'Tradición a pesar de todo o transformación a cualquier precio? En: DELGADO CONTRERAS, Camilo y NARVAÉZ TIJERINA, Adolfo (coordinadores). La experiencia de la ciudad y el trabajo como espacios de vida. Tijuana, B.C.: El Colegio de la Frontera Norte.

Shin, H. B. (2010). Urban conservation and revalorisation of dilapidated historic quartrs: The case of Nanluoguxiang in Beijing. Cities, 27, S43-S54. Recuperado de: <https://doi.org/10.1016/j.cities.2010.03.006>.

Tallon, A. (2013). Urban regeneration in the UK. London: Routledge.

UN-HABITAT (2004). Cultural strategies for urban development. In: United Nations Human Settlements Programme. The estate of the world cities 2004/2005. Globalization and urban culture. London: Earthscan, 2004, p. 31-48. Recuperado de: <http://dx.doi.org/10.18356/d1ef8074-en>.

Yúdice, G. (2008). Modelos de desarrollo cultural urbano: ¿gentrificación o urbanismo social?. Alteridades, 18(36), 47-61.

Zukin, S. (1987). Gentrification: culture and capital in the urban core. Annual review of sociology, 13(1), 129-147. Recuperado de: <https://doi.org/10.1146/annurev.so.13.080187.001021>.

Zukin, S. (1995). The culture of cities. Oxford and Cambridge: Blackwell Publishers. 